\title{
Social Aspects of Diagnosis and Treatment of Non-palpable Breast Lesions. Important Factor affecting Quality of Life in Cancer Patients undergoing Surgery
}

\author{
M. Bakos (Marian Bakos)1', T. Jankovic (Tomas Jankovic)ㄱ, V. Krcmery \\ (Mladimir Krcmery)2 ${ }^{2}$ M. Dubovcova (Martina Dubovcova) ${ }^{3}$
}

${ }^{1}$ Department of Surgery Faculty Hospital Nitra, Slovakia

Original Article

${ }^{2}$ University of Health and Social Work St. Elizabeth and Institute of tropical

Medicine Slovak Medical University Bratislava, Bratislava, Slovakia

${ }^{3}$ University of Health and Social Work St. Elizabeth, St. Lesley College, Nove Zamky, Slovakia

\section{E-mail address:}

bamamedchirurgia@gmail.com

\section{Reprint address:}

Marian Bakos

Faculty Hospital Nitra

Department of Surgery

Nitra

Slovakia

Source: Clinical Social Work and Health Intervention

Volume: 12

Issue: 2

Pages: $25-30$

Cited references: 25

\section{Reviewers:}

Jirina Kafkova

MSF, Freetown, SL

Roberto Cauda

Institute of Infectious Diseases, Catholic University of the Sacred Heart, Rome, IT

\section{Keywords:}

Breast Cancer. Non-palpable Lesion. SNOLL. Social Aspect. Quality of Life.

\section{Publisher:}

International Society of Applied Preventive Medicine i-gap

CSWHI 2021; 12(2): 25 - 30; DOI: 10.22359/cswhi_12_2_04 CC Clinical Social Work and Health Intervention

\section{Abstract:}

Introduction: The social aspect of breast cancer presents a serious problem all the time. Quality of women's life after surgery must be compared to life before it. Breast cancer treatments today are likely to cause less physical deformity from surgery than two decades ago but are more complex and extend over a longer period of time. Non-palpable breast lesions are findings with non-biologically specified importance, which can be responsible for development of cancer. The authors present the diagnosis and the results of the treatment of patients with non-palpable breast lesions. They were hospitalized at the Department of Surgery in Nitra from Jan- 
uary 2014 until July 2017 and we used the SNOLL method or wire guided excision under ultrasound control or digital stereotaxic.

Results: From January 2014 until July 2017 there were 122 patients diagnosed with non-palpable breast lesions at the Department of Surgery at our hospital. $76(62.3 \%)$ of these patients were diagnosed with carcinoma. Wire Guided Localization was performed in $99(81.1 \%)$ patients; sentinel node was found in 41 (33.6\%) patients using the SNOLL method. From all the patients a reoperation was conducted in 4 cases $(3.3 \%)$ for close or positive margin status and in 3 cases $(2.5 \%)$ for false negative perioperative sentinel biopsy.

Conclusion: The technique combining 99mTc-MAA (albuminmacro aggregate marked by 99 Technecium) and nanocoloid is a reliable localization method for non-palpable lesions and sentinel nodes. SNOLL is a practical and oncological safe technique of excision of a subclinical lesion in combination with sentinel biopsy. This technique brings new visions for the future, especially for quality of life after surgery, changes in body image and sexuality.

\section{Introduction}

Breast carcinoma presents as a serious diagnosis for every woman. The stress of breast cancer was described as arousing depression, anxiety, and anger. Breast cancer treatments today are likely to cause less physical deformity from surgery than two decades ago but are more complex and extend over a longer period. Women today are very well informed about the details of their cancer diagnosis and prognosis and are increasingly involved in shared decision-making regarding treatment. Although serious depression is not seen in most breast cancer patients and survivors, many will experience treatment-related distress, fear of recurrence, changes in body image and sexuality, as well as physical toxicities that result from adjuvant therapy. This paper discusses the importance of identifying early stage of cancer as an important factor of quality of life after surgery.

With premalignant non-palpable lesions, we understand the spectrum of morphological changes in the tissue of the breast. These changes are risk factors for the formation of cancer. We call them high res or precancerous lesions. These findings are unclear biological behavior as cells show malign architectural features, and the proliferation is different than the normal regulation mechanism of an organism. What is especially important, they have no invasion ability or ability to create metastasis. These lesions threaten patients with formation of cancer, but the extent of risk is necessary to connect with pre-existing individual risk factors of every patient $[1,2]$. In the last decades, the incidence of non-palpable lesions of the breast is increasing, because of mammography and other exact imaging methods. [3, $4,5]$. As a result of this fact, there is the decrease of number of neoplasia's and reduction of their spreading into the axillar lymphatic nodes [6]. The ratio of non-palpable lesions at the time of diagnosis is $25-30 \%$ in countries with function screening. [7]. With the increasing diagnosis of non-palpable lesions at an early stage, correct and complex treatment process is more important. Successful intraoperative localization of non-palpable lesion is necessary for surgeons because of complete excision during the single intervention without extensive excision of healthy tissue. This is important for a quality of life after surgery.

There are two types of pre-invasive carcinomas, which are different in their features and clinical meaning:

- Ductal carcinoma in situ (DCIS) - is the most common type of non-invasive breast cancer. During the months and years, it can progress into this malign form $(50 \%)$. The best treatment method is a surgical operation. Approximately half of cases of local relapse is presented as invasive carcinoma.

- Lobular carcinoma in situ (LCIS) - is an area (or areas) of abnormal cell growth that increases a person's risk of developing invasive 
breast cancer later on in life - both forms ductal or lobular. Treatment strategy is not only operative, but also in primary or secondary prevention [8].

\section{Material and Methods}

\section{Diagnostics and Treatment}

Imaging methods have decisive meaning in diagnoses of small non-palpable and clinical silent carcinomas. The method of choice is mammography. Mammography does not serve only for diagnosis of lesions in the breast, but it is useful in an intervention operation. Advantage of mammography is the ability to find micro-calcifications, which follow carcinoma in 30\%. With systematic mammography it is possible to decrease mortality [9].

Today the core-cut biopsy is the gold standard in preoperative diagnostics of non-palpable lesions of the breast. During the core-cut biopsy a roller of tissue is taken without damage to the architect of the tissue. It uses a special needle which is attached to a mechanical target unit. Today, there are many methods of preoperative localization of breast lesions. They must fulfill some basic conditions: the gold standard is localization of a non-palpable lesion with a wire (WGL - wire guided localization). By European guidelines for quality of screening and diagnosis of breast cancer the peak of wire must be in maximal $10 \mathrm{~mm}$ distance from the center of the lesions in a minimum of $90 \%$ of patients. In 1998 , at the Europe Oncological Institute, Luini introduced an alternative method of localization of a non-palpable lesion with the name ROLL (radio guided occult lesion localization) [9]. The principle of this technique is based on localization of a non-palpable lesion by radiopharmaceutical which is fixed on a carrier with a high molecular weight. Localization is conducted by ultrasonographic navigation, digital stereotaxic or magnetic resonance imaging. In patients with a non-palpable lesion of the breast evaluation of axillar lymphatic node is one of the most important factors, so the biopsy of sentinel node is very necessary. [10-14]. The combination of ROLL with a biopsy of the sentinel node is called SNOLL (sentinel occult lesion localization) and it was introduced by de Cicco in 2002 [15]. Localization is performed under ultrasonography navigation, digital stereotaxis or magnetic resonance imaging. It used the 99mTc-MAA (Technetium ${ }^{99 \mathrm{~m}} \mathrm{Tc}$ macro aggregated albumin), which is applied in a volume of $0.2 \mathrm{ml}$ with low activity. Indication is exact localization of small deep nonpalpable lesions of breast under $10 \mathrm{~mm}$ before surgery. Pregnancy and lactation are contraindications. The first phase of examination takes 1530 minutes and radiation load is minimal [16, 17]. Benefits of the ROLL/SNOLL method are: - it is more precise than the localization with wire, especially in a compact mammary gland - average time of operation is reduced

- lesions are in the resected tissue placed more in centre, they have wider resection border by the smaller volume of extirpation tissue

- increase in percent of non-pathological resection border

- decrease in the percent of require reoperations - diminish of operations wound and it is less traumatic [18, 19]

In our clinic, we proceed according to this two-days protocol:

1 First phase - indication - indication of the lesion by $99 \mathrm{mTc}-\mathrm{MAA}$, which is collected right in tumor without any extra-tumor spreading. Examination is possible to accompany with radionuclide detection of sentinel lymphatic node (SNOLL)

2 Second phase - perioperative localization - surgeons by the handy gamma probe localize the place with maximum radioactivity on the surface of the breast. Measurement of impulse of extirpation lesion and its border in the operation field is necessary for information about complete extirpation.

Imaging of the sentinel node is done by twodays protocol by application of nano nuclides with molecular weight $100-600 \mathrm{nM}$ and 99mTc subdermal peri-areolar in a dose of $60 \mathrm{MBq}$ patent blau. Control scintigraphy confirmed the locale and number of hot nodes. Localization of the nonpalpable lesion was done the day before surgery by the application of Technetium ${ }^{99 \mathrm{~m}} \mathrm{Tc}$ macro aggregated albumin with a molecular weight $10-$ $100 \mu \mathrm{m}$ in a radioactive dose of $20 \mathrm{MBq}$. Under USG control, respectively under digital stereotaxy. 94\% of lesions were marked at a distance of $10 \mathrm{~mm}$ from the center of the lesion. The non-palpable lesion and the sentinel node were detected by the gamma probe during the surgery. 
Operation preparation was subjected to an RTG examination for evidence of the lesion and width of a healthy resection border. In case the safety rim was under $10 \mathrm{~mm}$, the perioperative resection was done. Reoperation was conducted only if the safety rim was less than $3 \mathrm{~mm}$ in correlation of histopathological examination.

\section{Results}

From January 2014 to July 2017, we operated on 122 patients with non-palpable lesions of the breast. The carcinoma was confirmed for 76 patients $(62,3 \%)$. The average age of patients in our group was 63.5 years. Carcinoma was confirmed before surgery for 42 patients $(34.4 \%)$ by corecut biopsy and for 34 patients $(27.9 \%)$ the carcinoma was confirmed during the perioperative refrigeration. For 65 patients (53.3\%) after imaging non-palpable lesions core-cut biopsy was done (under the USG navigation and mammography). Image lesions were smaller than $1 \mathrm{~cm}$ or the cluster of micro-calcifications was detected. After the results of core-cut biopsy the carcinoma was confirmed for 42 patients (34.4\%) before surgery; for 23 patients $(18.9 \%)$ only benign lesion was detected). Localization of non-palpable lesion were done for 99 patients $(81.1 \%)$ with an identification wire. Altogether with localization of lesion with WGL we marked lesions with radiopharmaceutical for 87 patients $(71.3 \%)$. For 12 patients $(9.8 \%)$ we applied patent blau for visualization. We did lymphoscintigraphy for every patient who had suspicion of carcinoma - it means for 99 patients $(81.1 \%)$. At the beginning of surgery, we extirpated the suspect lesion and after this, the tissue was subjected to RTG because of the presence of clusters of micro-calcifications. After this, the histopathological examination was done. In case the safety rim was under $3 \mathrm{~mm}$ in correlation with the histopathological examination the re-resection was positive for 6 patients $(4.9 \%)$; for 35 patients $(28.37 \%)$ it was negative. The average amount of eliminated sentinel nodes for one surgery was 2.6.

After the confirmation of carcinoma from perioperative refrigeration, we indicated SNOLL for 41 patients $(33.6 \%)$. Non-palpable lesions were extirpated for 99 patients $(81.1 \%)$. If the result from core-cut biopsy was a benign lesion, we did not perform any surgery. We did reoperation for 7 patients $(5.7 \%)$; four times $(3.3 \%)$ it was because of insufficient border; three times $(2.5 \%)$ because of false negative result from perioperative histology of the sentinel node. Correlation of lesion's size in histopathological examination to number of reoperations is in table 1 .

Benign lesions we noticed in ages of 18-65 by $37.7 \%$ patients from the entire group. Malign lesions were characteristic for later incidence at ages 51-80 for $62.3 \%$ of patients. Occult, nonpalpable lesions, benign or malign are characterized by relative short anamnesis until surgery. Malign lesions were presented by a size of $10 \mathrm{~mm}$ in $94 \%$. Benign lesions were described connection with micro-calcifications in $55.8 \%$. It is important to do dispensing of these patients in specialized a an outpatient department. We found CIS for $14.8 \%$ patients in our group. CIS together with the T1 stage of carcinoma presented $46.05 \%$ from all malign cases $(76=100 \%)$.

\section{Discussion}

Examination of asymptomatic women increase capture of non-palpable lesions of the breast. Identification with guide wire remains standard for finding non-palpable lesions in many workplaces in Europe despite its deficiencies. These are, for example: difficulty for coordination of more specialists in delimited time, ac-

Tab. 1: Correlation of lesion size in histopathological examination to number of reoperations

\begin{tabular}{|c|c|c|c|c|c|}
\hline \multirow[b]{2}{*}{ pT } & \multirow[b]{2}{*}{$n$} & \multirow[b]{2}{*}{$\begin{array}{l}\text { Verification of } \\
\text { SNL (SNOLL) }\end{array}$} & \multirow[b]{2}{*}{$\begin{array}{l}\text { identification } \\
\text { with WGL }\end{array}$} & \multicolumn{2}{|c|}{ Reoperation- (border $<3 \mathrm{~mm}$ ) } \\
\hline & & & & $\begin{array}{l}\text { Insufficient } \\
\text { border }\end{array}$ & $\begin{array}{c}\text { False negative } \\
\text { finding from } \\
\text { SNB }\end{array}$ \\
\hline Tis & 18 & 2 & 23 & & \\
\hline T1a & 17 & 7 & 26 & & \\
\hline T1b & 22 & 18 & 28 & 2 & 1 \\
\hline T1C & 19 & 14 & 22 & 2 & 2 \\
\hline overall & 76 & $41 / 122(33.6 \%)$ & 99/122 (81.1\%) & $4 / 122(3.3 \%)$ & $3 / 122(2.5 \%)$ \\
\hline
\end{tabular}


cumulation of stress factors because of more invasive processes on surgery day: vaso-vagal syncope during the localization; dislocation; migration; transection of a wire; thermic damage of skin during surgery; injury of surgeon or pathologist by processing of tissue [19].

In 1998, Luini introduced a new method with the name ROLL. Principle of this technique is based on localization of sentinel node by radiopharmaceutical which is fixed on a carrier with a high molecular weight. Some randomized studies were conducted with this method. De Cicco in a group of 227 patients combined two kinds of radio carriers with position variations of application of radiopharmacology. They have found that the most optimal for imaging of tumor is an intratumor application of Technetium ${ }^{99 \mathrm{~m}} \mathrm{Tc}$ macro aggregated albumin in combination of a subdermal peri-areolar ap-

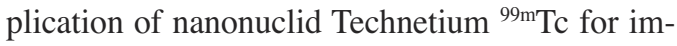
aging of a sentinel node. [15]. Verification of a node was demonstrated for $99 \%$ of patients. Monti et al. have publicized the most extensive study of 959 patients with carcinoma of the breast using the SNOLL. The study was focused for verification of the sentinel node and oncology radicality with using SNOLL [20]. Localization of a node was demonstrated in $99.6 \%$ of patients,; while negative borders were found in $91.9 \%$. A negative border was presented by a safety rim $>10 \mathrm{~mm}$. There were presented some studies with intratumor application of nanonuclid for simultaneously localization tumor and sentinel node [18]. Moreno has randomized a group of 120 patients into 2 groups [14]: ROLL a WGL. He identified: the safety of the resection border; cosmetic effect; and measure of postoperative pain in the first postoperative day. He defined safety borders of $10 \mathrm{~mm}$ for invasive carcinoma and $5 \mathrm{~mm}$ for DCIS. Both methods safely localized the non-palpable lesion. In the ROLL group a statistically significant higher number of clear borders $(p<0,05)$ was observed; better esthetic results; less postoperative pain which resulted in shorter hospitalization.

There is a new method for detection of a sentinel node which is called Sentimag. The Sentimag instrument uses the principle of magnetic susceptometry and generates an alternating magnetic field which transiently magnetizes the iron oxide particles in Sienna+. One of the benefits of Sienna+ is that this substance is not radioactive [21.22].
In concussions of overview studies, radiopharmacological navigated localization obtained many supporters. The reasons are a smaller number of reoperations and better cosmetic effect. Popularity of this method is enhanced with its combination of biopsy of sentinel node. Incidence of CIS dos does not reach $2 \%$ over a long term period in Slovakia, in screening programs its incidence raised [23]. Identification of nonpalpable lesions and micro-calcifications before surgery is important for breast carcinoma because early identification requires minimal surgery and minimal multimodal therapy. We can expect minimal incidence of local relapses, higher survival of patients and decrease of mortality. We expect more significant effect in survival of patients with non-palpable lesions of mammal gland (CIS, tumor in T1a) by using MRI with a contrast substance and follow-up marked by guide wire before surgery. SNOLL is a very practical modification of ROLL method in practice. With a combination of sentinel node detection, it is useful and oncological safety technique of excision of subclinical lesion [23. 24].

\section{Conclusion}

In pursuance of our study's results, we can state that detection of sentinel node using $99 \mathrm{mTc}-$ MAA presents a reliable method for localization of non-palpable lesions and sentinel node. SNOLL in combination with sentinel node detection is practical and an oncological safety technique of excision of a subclinical lesion. Alternative method of localization of sentinel node is method Senti-Mag. Benefit of this method is that substance Sienna+ is not radioactive.

Examination of asymptomatic women increases the number of non-palpable malign lesions of the breast. This technique brings new visions for the future, especially for: quality of life after surgery; changes in body image; and sexuality. Identification of a non-palpable lesion with a guide wire still the gold standard for its verification in many workplaces in Europe. Whether breast cancer patients are newly diagnosed, survivors, or at the end of life, attending to their psychological and social concerns will enhance the effectiveness of our treatments and palliation of symptoms. New techniques in diagnosis or in surgery are helpful for better quality of women's life with breast cancer. 


\section{References}

1. LEBEAU A (2010) Precancerous lesions of the breast. Breast Care. 5: pp 204-206.

2. SINN HP et al. (2010) Early breast cancer precursor lesions: Lessons learned from molecular and clinical studies. Breast Care. 5: pp 218-226.

3. KOHLER BA et al. (2015) Annual report to the nation on the status of cancer, 1975-2011, featuring incidence of breast cancer subtypes by race/ethnicity, poverty and state. J Natl Cancer Inst. 107:djv048.

4. HORTOBAGYI GN et al. (2005) The global breast cancer burden: variations in epidemiology and survival. Clin Breast Cancer. 6: pp 391-401.

5. DEFELICE C et al. (2012) The impact of presurgical magnetic resonance in early breast cancer: an observational study. Eur J Gynaecol Oncol. 33: pp193-9.

6. CADY B et al. (1996) The new era in breast cancer: invasion, size, and nodal involvement dramatically decreasing as a result of mammographic screening. ArchSurg. 131: pp 301-8.

7. BERRY DA et al. (2005) Effect of screening and adjuvant therapy on mortality from breast cancer. N. Eng J Med. 353:1784-92.

8. COUFAL O, FAIT V, EDITORS (2011) Surgical treatment of breast carcinoma. Grada. 76, 255, ISBN 978-80-247-3641-9. Grada. $76,255$.

9. LUINI A et al. (1998) Radio guided surgery of occult breast lesions. Eur J Cancer. 34: pp 204-205.

10. SAJID MS et al. (2012) Comparison of radio guided occult lesion localization and wire localization for non-palpable breast cancers: a meta-analysis. J Surg Oncol. 105:852-8.

11. LOVRICS PJ et al. (2011) Systematic review of radio guided surgery for non-palpable breast cancer. Eur J SurgOncol. 37: pp 38897.

12. MEDINA-FRANCO, H et.al. (2008) Radio guided occult lesion localization (ROLL) versus wire-guided lumpectomy for non-palpable breast lesions: a randomized prospective evaluation. J SurgOncol. 97: pp 108-11.

13. LOMBARDI A et al. (2015) High-resolution, hand held camera use for occult breast lesion localization plus sentinel node biopsy
(SNOLL): A single-institution experience with 186 patients. Surgeon. 13: pp 69-72.

14. MORENO M et al. (2008) Radio guided breast surgery for occult lesion localization: correlation between two methods. J ExpClinCancerRes. pp 27:29.

15. DECICCO C et al. (2002) Radio guided occult lesion localization (ROLL) and surgical biopsy in breast cancer. Technical aspects. Q J Nucl Med. 46: pp 145-151.

16. NURKO J, MICHAEL JE (2005). Imageguided breast surgery. Am J Surg. 190: pp 221-7.

17. GUTH A (2019) Operate or rehabilitate, Rehabilitation, Vol 56, No 4, 2019 , ISSN 03750922, p. 168-169.

18. GITTLEMAN MA (2003) Single - step ultrasound localization of breast lesions and lumpectomy procedure. Am J Surg._186: pp 386-90.

19. LAVOUE V et al. (2008) Simplified technique of radio guided occult lesion localization (ROLL) plus sentinel lymph node biopsy (SNOLL) in breast carcinoma. Ann Surg Oncol. 15: pp 2556-2561.

20. MILES DUA S, GRAY RJ, KESHTGAR M (2011) Strategies for localization of impalpable breast lesion. The Breast. 20: pp 246253.

21. MONTI S et al. (2007) Occult Breast lesion Localization plus Sentinel Node Biopsy (SNOLL): Experience with 959 Patient at the European Institute of Oncology. Ann Surg Oncol. 14: pp 2928-2931.

22. DOUEK M et al. (2014) Sentinel node biopsy using a magnetic tracer versus stardard technique: the SentiMAG Multicentre Trial. Ann Surg Oncol. 21: pp 1237-45.

23. COUFAL O et al. (2015) SentiMag--the magnetic detection system of sentinel lymph nodes in breast cancer SentiMag Rozhl Chir, 94: pp 283-288.

24. TURCAN I et al. (2013) Surgical treatment of non palpable breast cancer by SNOLL method. Slov. chir.10: pp 56-58.

25. CARRERA D et al. (2017) Use of the ROLL technique for lumpectomy in non-palpable breast lesions. Rev Esp Med Nucl Imagen Mol. 2017; 36(5): pp 285-291. 